\title{
Analysis of the causes of failure in 5Cr-1Mo pipes mounted in a preheating furnace
}

\author{
Adelina Borruto \\ Dept. of Chemical and Mat. Engineering "La Sapienza", Via Eudossiana 18 - 00184, Rome, Italy \\ adelina.borruto@uniroma1.it \\ Giovanni Narducci \\ Dept. of Chemical and Mat. Engineering "La Sapienza", Via Eudossiana 18 - 00184, Rome, Italy \\ giovanni.narducci@uniroma1.it
}

Pietro Pietrosanti

Technip S.p.A Viale Castello della Magliana, 6800148 Roma

ppietrosanti@technip.com

\begin{abstract}
The oxidation resistance of iron-based alloys depends on the formation of thin protective films consisting of reaction products between the alloys and the ambient atmosphere. The high corrosion resistance of $\mathrm{Fe}-\mathrm{Cr}-\mathrm{Mo}$ alloys has been attributed to the rapid formation of a uniform, highly protective passive film. The pipes hardness and resistance to various forms of corrosion are determined by the composition of the oxide layer that plays an important role in determining the lifetime of the pipes themselves. The thermal stability of the oxide layer is influenced by its composition and thickness as well as by the bond to the underlying metal.

Determining factors for the high temperature corrosion are generally: temperature, metallurgy, TAN (chloridric and naphthenic acid), local flow conditions, sulphur compounds.
\end{abstract}

KEYwORDS. Low carbon steel; Corrosion products; Total Acid Number; Sulphur compounds.

\section{INTRODUCTION}

7 he Cr-Mo steels are excellent structural materials that are used in power generation and petrochemical industry: typical products for these industries are boiler, heater, heat exchanger, reactors and hydrocrackers, usually build as heavy wall pressure vessels [1]. These steels are also used for turbine rotor of high-temperature and high-pressure power plant.

The Cr-Mo steels combine, on one hand, creep resistance, strength and toughness that can be achieved through tempering, and, on the other hand, high corrosion resistance. In particular, $\mathrm{Fe}-5 \mathrm{Cr}-1 \mathrm{Mo}$ steel is used as corrosion resistant alloy in petrochemical plants.

The oxidation resistance of $\mathrm{Fe}-\mathrm{Cr}$ alloys depends on the formation of thin protective films consisting of the products of the reaction between iron-based alloys and the ambient atmosphere [2-5].

The characteristics of the oxide layer formed on the surface of a steel element play a significant role in determining the lifetime of the element itself.

The thermal stability of the oxide layer is influenced by the composition and thickness of the oxide layer as well as the bond to the underlying metal [6].

However, the tempered Cr-Mo steels must be used judiciously in structures exposed to hydrogen gas [7]. 
An analysis of $\mathrm{Cr}-\mathrm{Mo}$ steels pipes corrosion is carried out in this paper. The internal surface of pipes has been exposed to a corrosive environment and the effect will be showed.

\section{EXPERIMENTAL}

he corrosion of pipes in a furnace used to preheat crude oil in an atmospheric distillation plant was considered. The observed pipes are made of Cr-Mo steel, as it will be shown later by EDS analysis. The dimensions of the asreceived pipes are as follows: external diameter $115 \mathrm{~mm}$, thickness 4,3 $\mathrm{mm}$.

Before investigation, the pipes were exposed to in service conditions for about four years.

Over the first two years, the pipes worked with a constant composition and flow rate crude oil-fed:

a) charge: 480 ton/h of crude (48\% Arabian Light crude and 52\% Arabian Medium crude);

b) feed charge states in the furnace: at entrance, liquid; at exit, partly vapour;

c) the furnace temperatures: at entrance, $340^{\circ} \mathrm{C}$; at exit, $400^{\circ} \mathrm{C}$;

d) average speed of fluid in the pipes in the furnace: $2.1 \mathrm{~m} / \mathrm{s}$;

e) sulphur percentage $\mathrm{S} \%=2.12$;

f) TAN of the feed charge entering the furnace 0.1 .

During year 3 the charge of the crude oil was modified. The Fig. 1 shows the trend of the charge v.s. the time (month) and highlights the following differences in crude composition:

1) Arabian Light: a maximum equal to $95 \%$ in the feed takes place in April month. This value remains steady AT $60 \%$ in the following month.

2) Arabian Medium: its percentage in the feed falls to $0 \%$ in April, along with the increase in Arabian Light's percentage. The flow rate of Arabian Medium increases in May and reaches about $21 \%$ in the following months.

3) Ural: low percentages (about 13\%) have been present since January. Maximum value of 37\% takes place in May, and then stabilizes at $11 \%$.

4) Since May small amounts (about $2 \%$ ) of Buri, Kirkuk, Iranian Heavy and Bonny Light were added.

The crude composition in December was: 61.93\% Arabian Light, 14.16\% Arabian Medium, 23.91\% of different feeds (4.9\% Ural, 11.05\% Kirkuk, 5.93\% Buri and 2.03\% Bonny Light). This data are processed in the atmospheric distillation unit.

The flow rate composition (weight $\%$ ) of the crude oil blend feeding the atmospheric distillation unit was measured in the last three day of every month. Given that the three readings did not differ much, the average value has been used as representative information for each month. To make the graph easier to read and understand, the markers have been connected to each other.

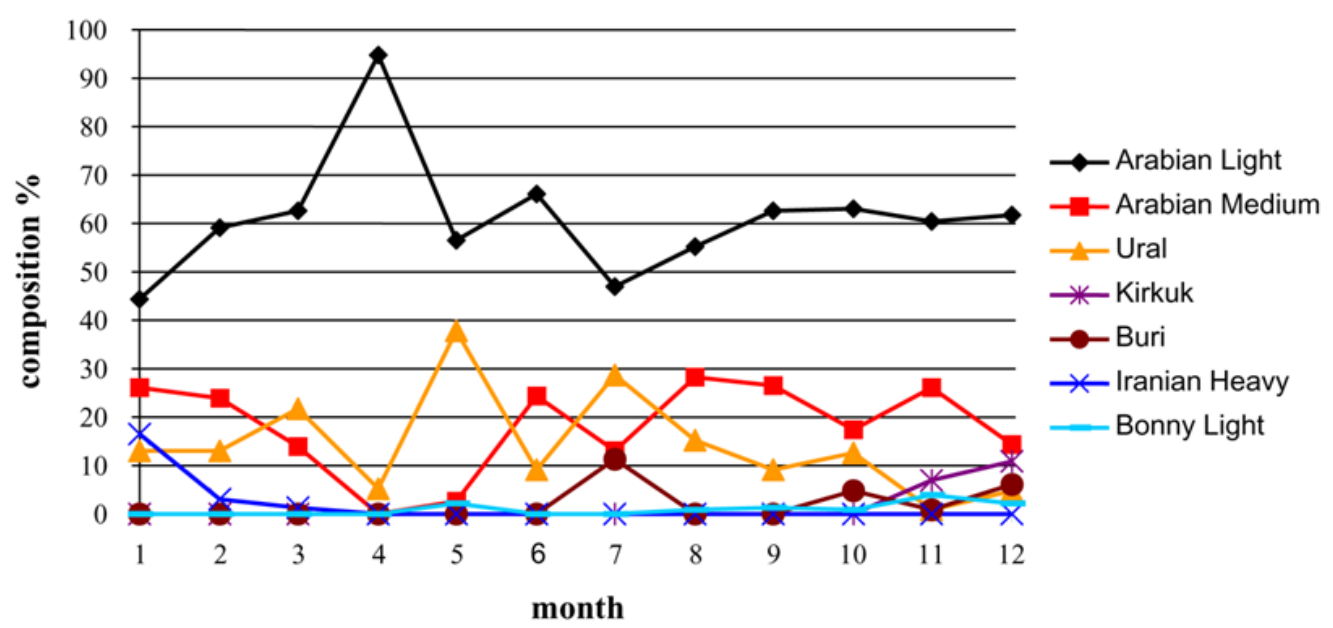

Figure 1: Crude composition (weight \%) during the penultimate operating year.

During the last operating year another variation in the charge of the crude oil was observed. Fig. 2 shows the trend of the charge v.s. time and highlights the following differences on crude composition: 
1) Arabian Light: the medium percentage is $45 \%$, characterized by two negative peaks, the first one in June (29.01\%) and the second one in November $(31.77 \%)$.

2) Arabian Medium: the medium percentage is $24 \%$ till June and nears $0 \%$ in September.

3) Ural: the medium percentage is very low till May (6.6\%), then, after May, it remains at $21 \%$.

4) Basrah: this crude is added in a small percentage till March $(3.2 \%)$.

5) Buri: the medium percentage is about 11\% from January to March, at $0 \%$ in April, May, June and $13 \%$ from July to November.

6) Iranian Heavy: this crude is fed in April; the medium percentage remains at $18 \%$ in the following months.

7) Bonny Light: this crude is added in very small percentages till June (1.5\%).

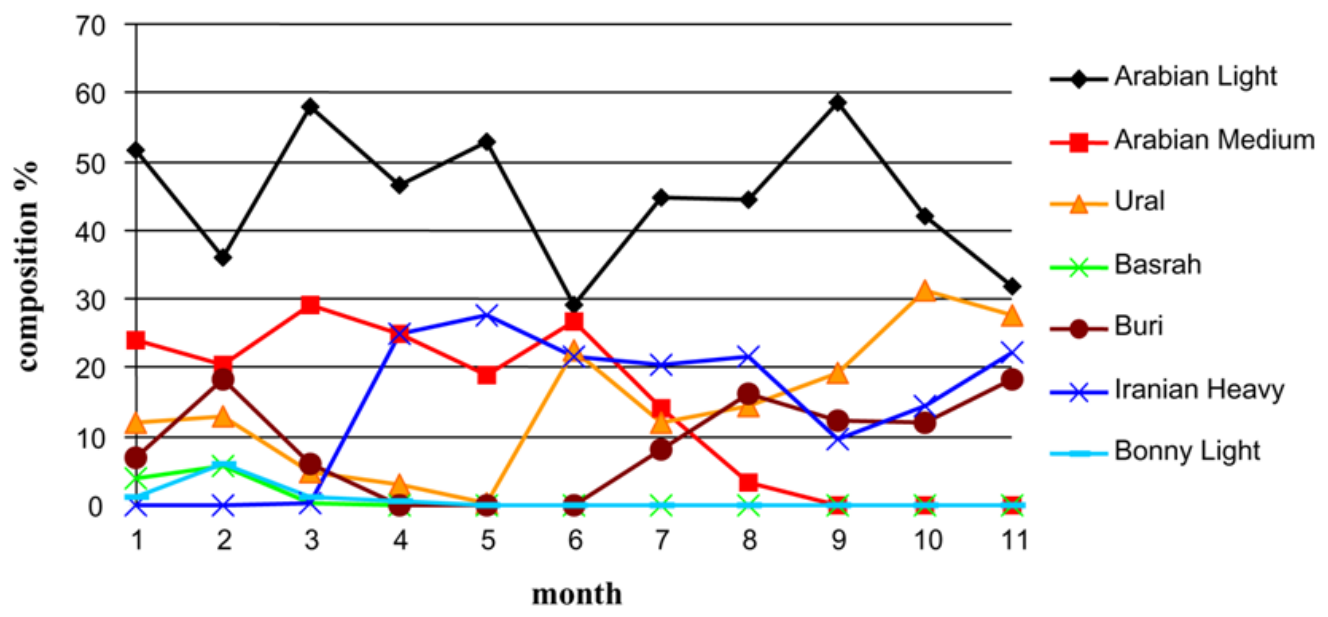

Figure 2: Crude composition (weight \%) during the last operating year.

In November the feed's composition was: 31.77\% Arabian Light, 27.67\% Ural, 18.36\% Buri and 22.20\% Iranian Heavy. As a consequence of this crude oil charge, a variation in the working conditions of the pipes is observed:

$\checkmark \quad$ sulphur percentage entering the furnace $\mathrm{S} \%=3.3$;

$\checkmark \quad$ TAN of the feed charge entering the furnace 0.39 .

Annual graphic of the crude blending mass rate $G_{M}(t / h)$ in function of time (month) is shown in Fig. 3. In the penultimate operating year a relevant but slow decrease in the flow rate is shown from January to April. A fast increase occurred from April to May.

During the last operating year, again, a flow rate decrease is noticed in April, but this is negligible compared to the one which occurred in the penultimate operating year.

The data processed in the atmospheric distillation unit shows that the thickness of the pipe walls during the last two operating years decreased from $7.14 \mathrm{~mm}$ to $4.30 \mathrm{~mm}$.

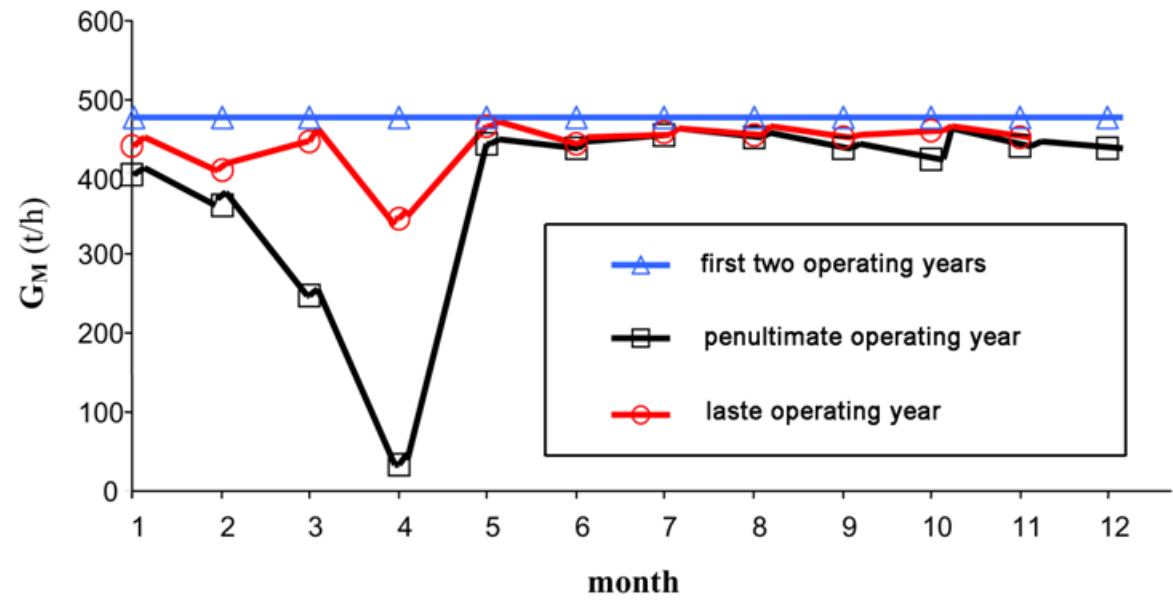

Figure 3: Comparison of crude blending mass rate v.s. the time. 


\section{RESULTS}

$\mathrm{T}$ he samples were taken from pieces of pipe removed from the furnace in the atmospheric distillation unit. The specimens were tested with macrographic and micrographic analysis (M.O.), electronic microscopy (SEM) and EDS analysis.

\section{Macrographic analysis}

The macrographic analysis shows two types of damage inside the pipe: pitting corrosion and areas with thickly oxidized scale presence (Fig. 4).

Fig. 5 is a magnification of a part of figure 4 and shows the presence of a large surface pit.

Fig. 6 is also a magnification of a part of figure 4: it highlights the deposits of the products of macroscopic corrosion, which are very coherent and thick. Areas with different colours are recognizable on the internal surface of the pipes, seemingly due to the presence of corrosion products such as $\alpha-\mathrm{Fe}_{2} \mathrm{O}_{3}$ (hematite) and $\gamma-\mathrm{Fe}_{2} \mathrm{O}_{3}$ (maghemite) respectively reddish brown and dark yellowish brown [8-9], besides $\mathrm{Fe}_{3} \mathrm{O}_{4}$ and $\mathrm{Cr}_{2} \mathrm{O}_{3}$ oxides. Each Fe oxide shows a colour that is a function of several factors including the electron transitions, the particle size and shape, crystal defects, adsorbed impurities, and the degree of particle packing [9]. Particularly, a reduction in particle size of Fe oxides results in paler colours, one exception is goethite [9-10].

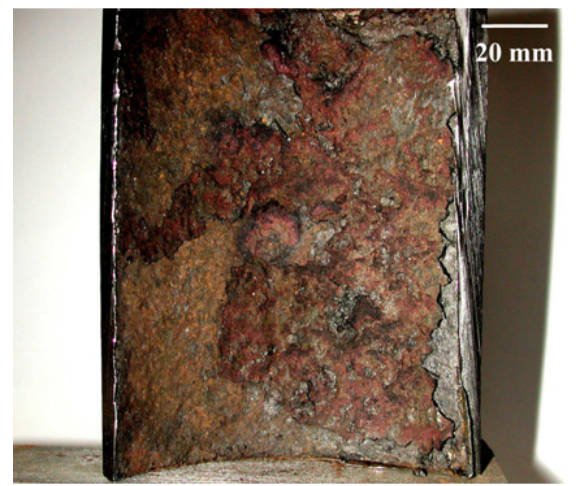

Figure 4: Macrographic analysis. View of the internal surface of a pipe take from a pre-heating fornace.

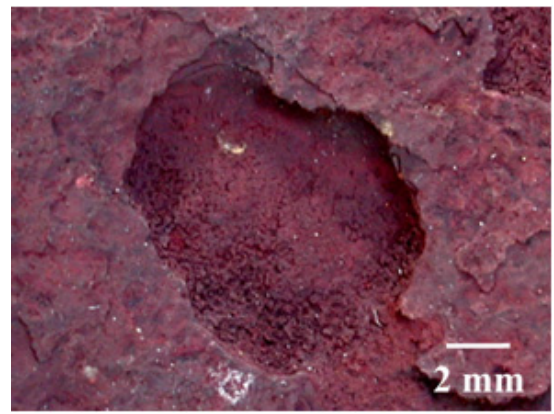

Figure 5: Macrographic analysis. Magnification of a detail from Fig. 4. Pitting corrosion.

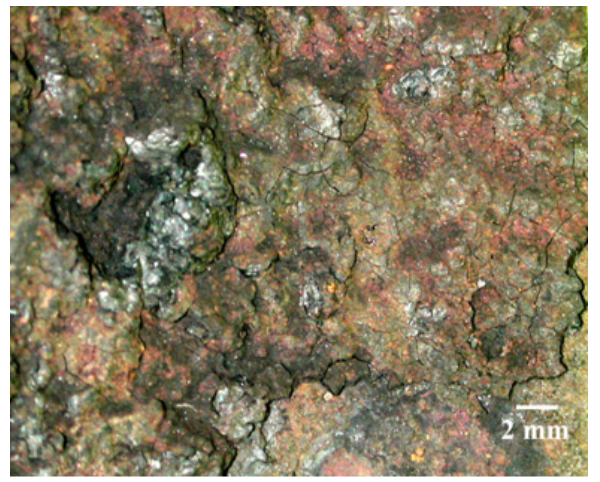

Figure 6: Macrographic analysis. Magnification of a detail from Fig. 4. Corrosion scale.

\section{Micrographic analysis (M.O.)}

Surfaces, showing pit and scale, were examined. Micrographic analysis was carried out, comparing the areas under the pit showed in Fig. 5, with those under the scales showed in Fig. 6.

For this purpose two samples were taken from the investigated corroded pipe as shown in Fig. 7.

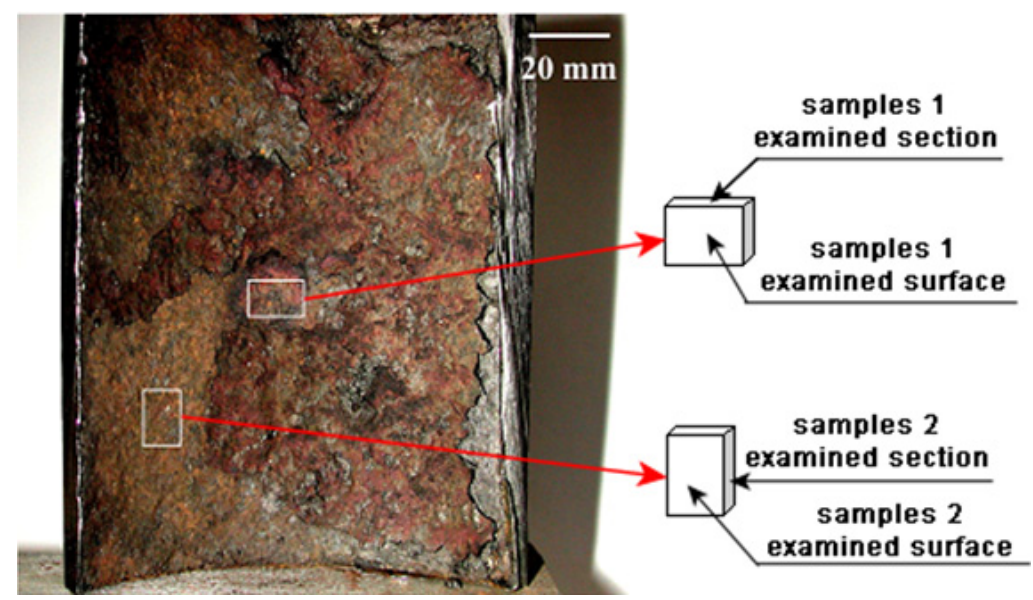

Figure 7: Areas of sampling; sample1: pit zone; sample2: scale zone. 
The top section of sample 1 (Fig. 7) was examined to investigate the region under the pit (Fig. 8). This region shows the presence of infiltrations that provoke new pits.

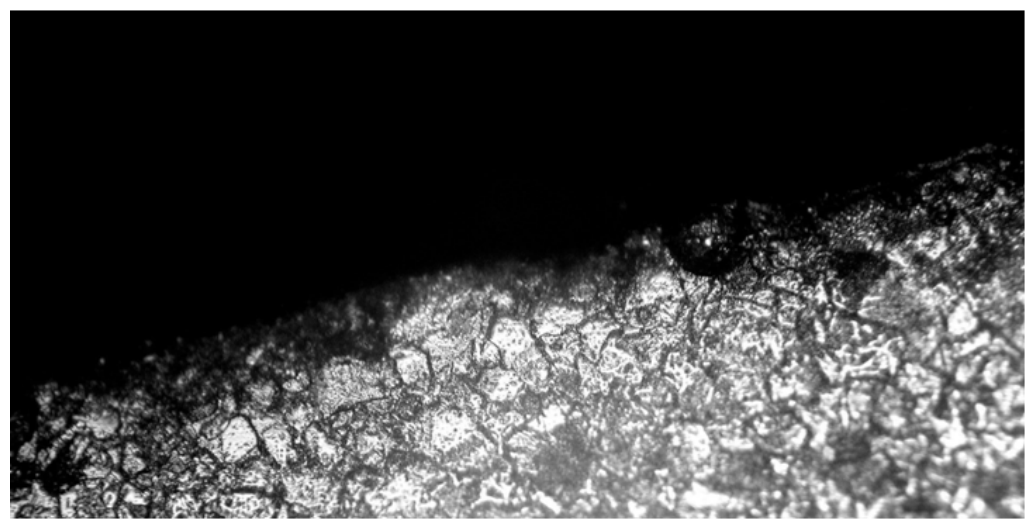

Figure 8: Micrographic analysis. Under site of large pit surface. Presence of infiltration that give birth to new pits. $-200 \mathrm{X}$.

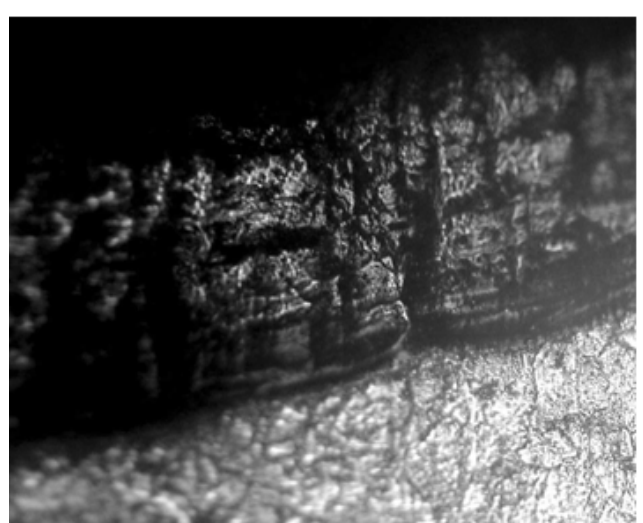

Figure 9: Micrographic analysis. Under site of scale surface. Discontinuous scale due to pronounced penetration. $-200 \mathrm{X}$.

The side section of sample 2 (Fig. 7) was examined to investigate the region under the scale (Fig. 9). This region shows a deep intergranular penetration. In fact the surface scale appears very discontinuous.

\section{Electronic microscopy (SEM) and EDS analysis}

The electronic microscopic analysis (SEM) was carried out. Again the pit and the scales were examined.

For each of the two samples previously taken, both sections already observed to $\mathrm{MO}$ and sides corresponding to the inner surface of the pipe were examined (Fig. 7).

$\underline{\text { Pit }}$

The surface of the pit valley was examined (Fig. 7 - sample 1 surface). Fig. 10 and its magnification, Fig. 11, show the surface of the pit valley, badly damaged and the porous and sponge-like scale, no longer protective. EDS analysis was carried out on this surface, and it showed the presence of chromium and sulphur, all elements related to corrosive products such as iron and chromium oxides (Fig. 12, Tab. 1).

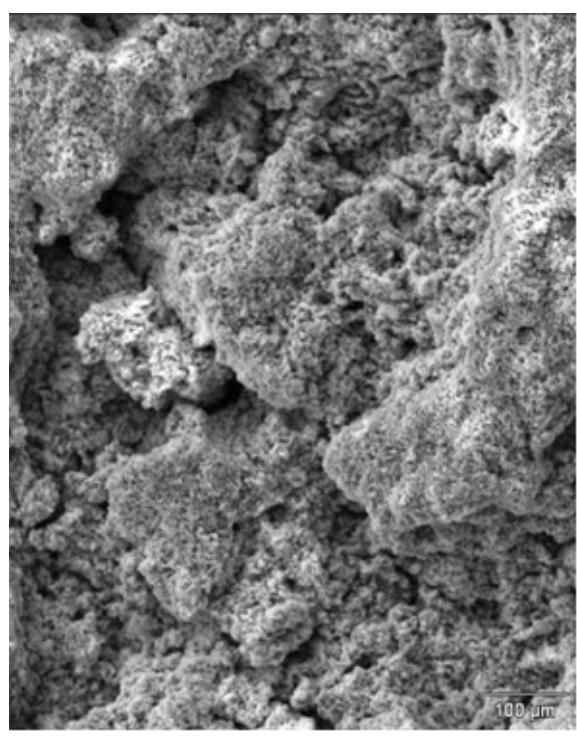

Figure 10: SEM analysis. Surface of the pit valley $-200 \mathrm{X}$.

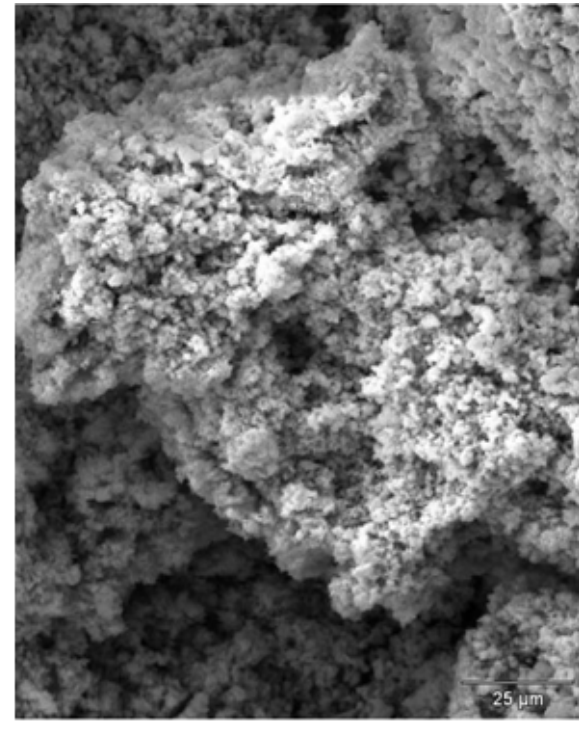

Figure 11: SEM analysis. Magnification of a detail from fig. 10. $-1000 \mathrm{X}$.

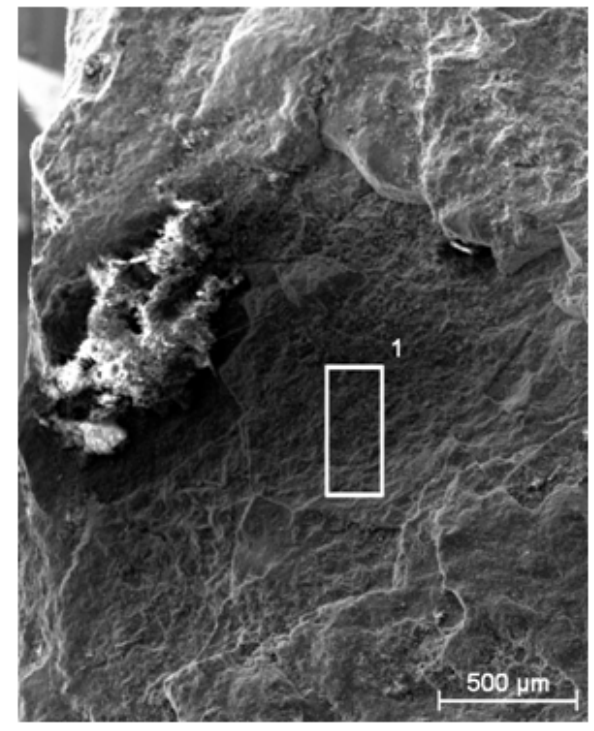

Figure 12: SEM analysis. Pit surface. - 60 $\mathrm{X}$. 


\begin{tabular}{ccccccc} 
& $\boldsymbol{A} \boldsymbol{l}$ & $\boldsymbol{S i}$ & $\boldsymbol{S}$ & $\boldsymbol{C r}$ & $\boldsymbol{F e}$ & $\boldsymbol{M o}$ \\
$\boldsymbol{p t 1}$ & 3.90 & 1.65 & 9.16 & 10.78 & 62.43 & 12.09 \\
\hline
\end{tabular}

Table 1: EDS analysis (weight $\%$ ) of areas shown in the Fig. 12.

A section of the pit was made (Fig. 7 - sample 1 section). The progress of the corrosive process under the macroscopic pit (Fig. 13) and the inter-granular damage (Fig. 14) were monitored.

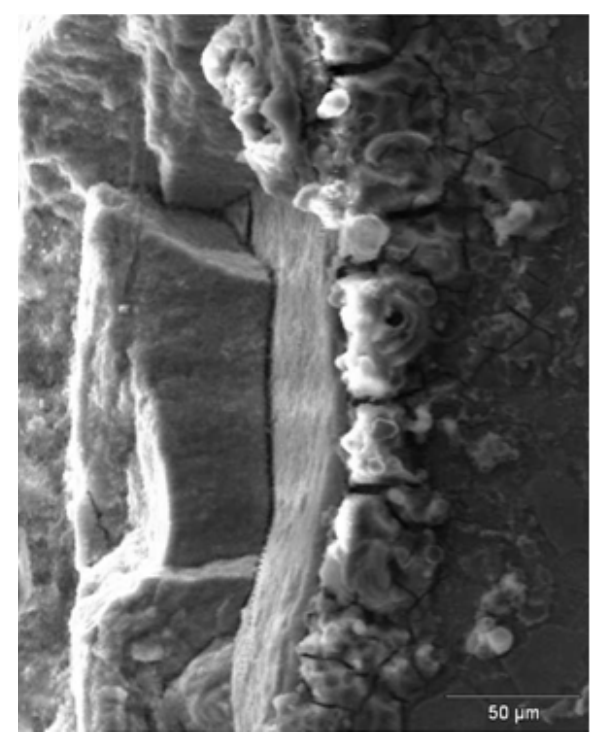

Figure 13: SEM analysis. Section view of the pit. Corrosive process. $-600 \mathrm{X}$.

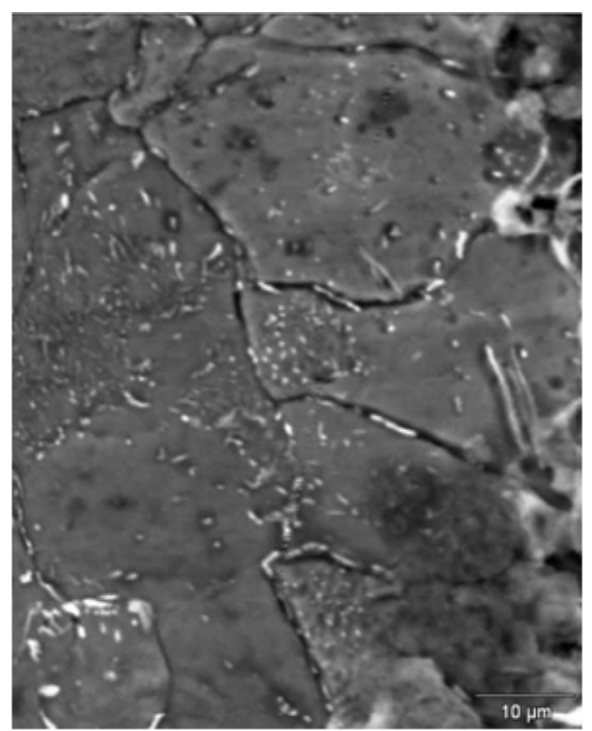

Figure 14: SEM analysis. Section view of the pit. Intergranular damage. - $2200 \mathrm{X}$.

\section{$\underline{\text { Scale }}$}

The pipe section scale was examined (Fig. 7 - sample 2 section):

internal pipe section: Fig. 15 shows an internal area of the pipe where the protective scale layer is still present, even if very thin; the scale appears damaged and penetrated, so that a significant fracture is present. EDS analysis (Tab. 2) shows in point 1, where the scale is compacted, a greater chromium concentration (probably $\mathrm{Cr}_{2} \mathrm{O}_{3}$ ) than in points 3, 4, where the oxidation is principally due to $\mathrm{Fe}_{2} \mathrm{O}_{3}$ and $\mathrm{Fe}_{3} \mathrm{O}_{4}$ oxides.

Considering the external pipe section scale: Fig. 16 shows a very porous and infiltrated surface, with relevant penetration of grain boundaries (Fig. 17).

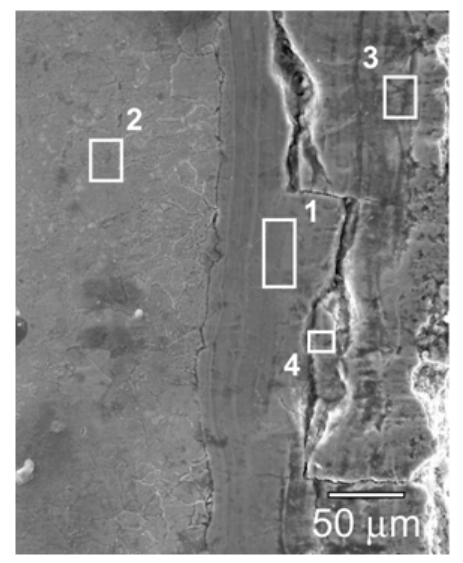

\begin{tabular}{l|cccccc}
\cline { 3 - 7 } & $\boldsymbol{O}$ & $\boldsymbol{S i}$ & $\boldsymbol{C r}$ & $\boldsymbol{M n}$ & $\boldsymbol{F e}$ & $\boldsymbol{M o}$ \\
\hline Pt 1 & & 1.30 & 20.39 & 2.63 & 72.72 & 2.97 \\
Pt 2 & & & 4.60 & & 95.40 & \\
Pt 3 & 95.29 & 0.04 & 1.38 & 0.13 & 3.17 & \\
Pt 4 & 95.98 & 0.03 & 1.01 & 0.12 & 2.86 & \\
\hline
\end{tabular}

Table 2: EDS analysis (weight $\%$ ) of areas shown in the Fig. 15.

Figure 15: SEM analysis. Internal area of pipe where protective scale layer is still present, even if very thin; the scale appears damaged and penetrated, so that a relevant fracture is present. $-400 \mathrm{X}$. 


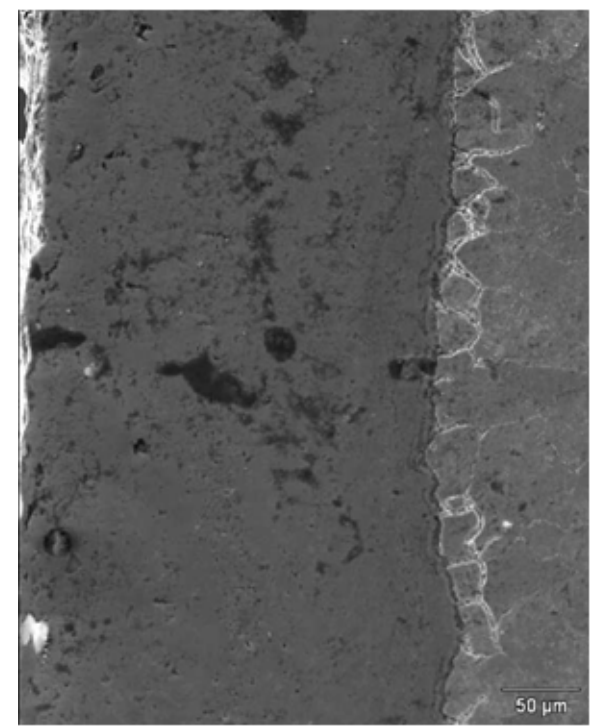

Figure 16: SEM analysis. External pipe section scale $-350 \mathrm{X}$.

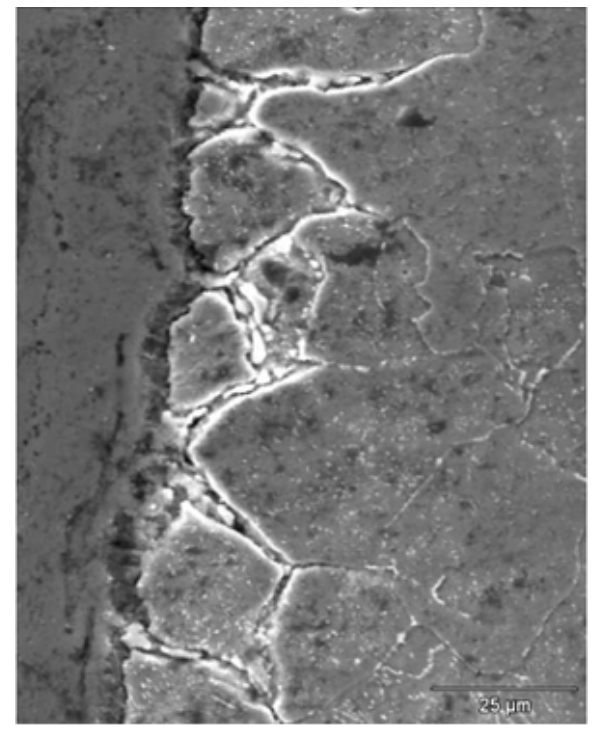

Figure 17: SEM analysis. Magnification of a detail from Fig. 16. $1300 \mathrm{X}$.

A map has been executed on a section of the scale (fig. 18). The map shows sulphur presence (sulphur compounds) at the interface between compressed and porous scale with a build-up immediately behind the compacted scale.

A major Cr concentration appears in the penetrated area, while the oxygen is diffused.

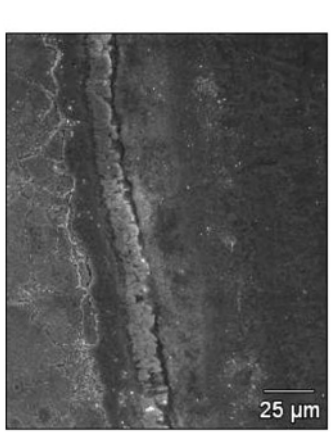

o

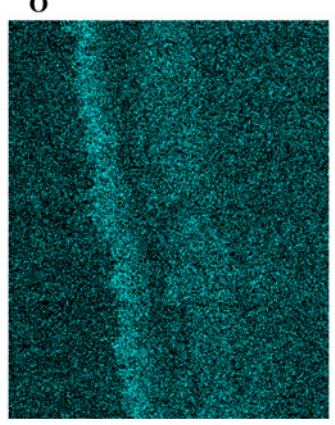

Figure 18: SEM analysis. Map of corrosion crust $-800 \mathrm{X}$.

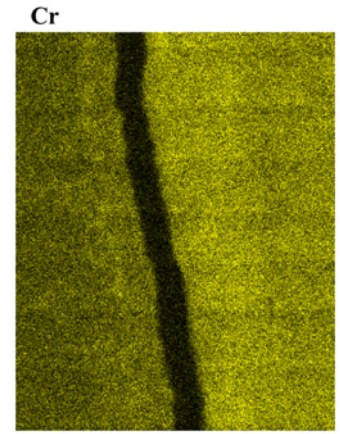

$\mathbf{S}$

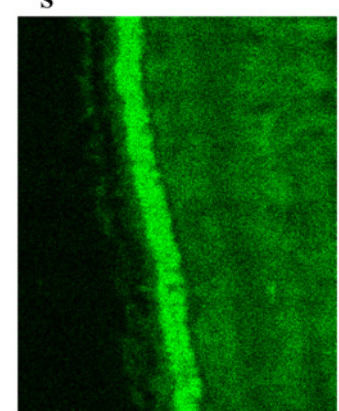

The pipe surface scale was examined (Fig. 7 - sample 2 section): micrographic analyses have been performed on particles removed from the surface scale. The following figures show two different crust types. The first one (Fig. 19) appears to be non homogeneous and porous. Channels rich in chlorine and sulphur formed by pressured gas are visible (Fig. 20), EDS analysis (Tab. 3).

The second crust type (Fig. 21) seems to be compacted, with sulphuric and chloride compounds present, as the EDS analysis detected (Tab. 4). 


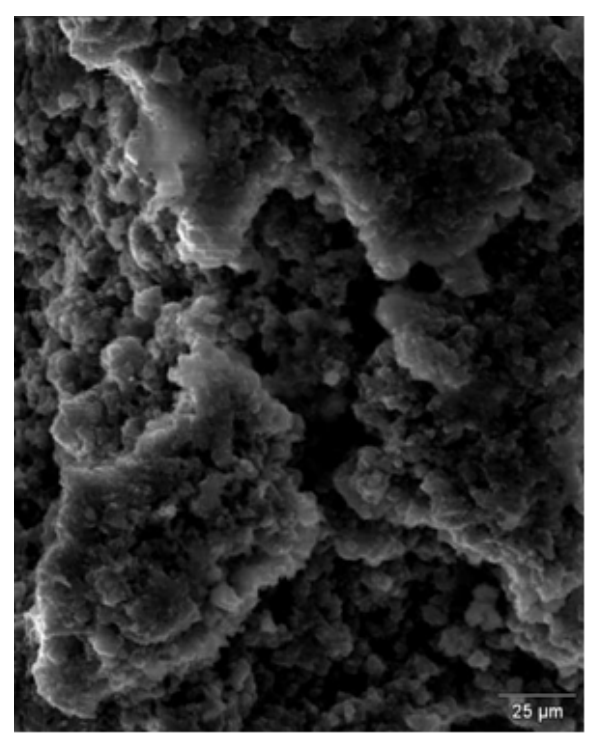

Figure 19: SEM analysis. Porous particles from the surface crust $-700 \mathrm{X}$.

\begin{tabular}{l|ccccccc}
\cline { 2 - 8 } & $\boldsymbol{C}$ & $\boldsymbol{N a}$ & $\boldsymbol{S i}$ & $\boldsymbol{S}$ & $\boldsymbol{C l}$ & $\boldsymbol{C a}$ & $\boldsymbol{F e}$ \\
\hline Pt 1 & 93.25 & & & 5.75 & 1.00 & & \\
Pt 2 & 95.59 & & & 3.81 & 0.60 & & \\
Pt 3 & 88.17 & 1.34 & 0.19 & 5.02 & 2.15 & 0.50 & 2.63 \\
\hline
\end{tabular}

Table 3: EDS analysis (weight $\%$ ) of areas shown in the Fig. 20.

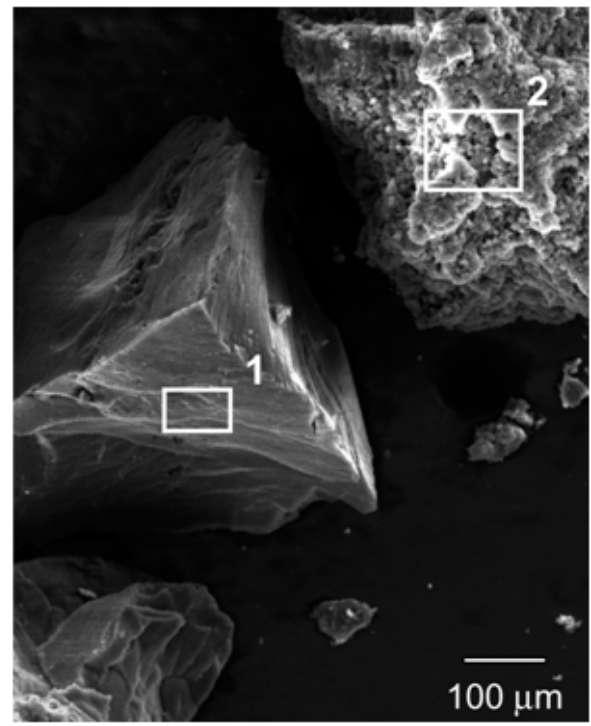

\begin{tabular}{c|cccc}
\cline { 2 - 5 } & $\boldsymbol{S i}$ & $\boldsymbol{S}$ & $\boldsymbol{C l}$ & $\boldsymbol{F e}$ \\
\hline Pt 1 & 7.48 & 45.50 & 14.17 & 32.85 \\
Pt 2 & & 31.66 & & 68.34 \\
\hline
\end{tabular}

Figure 21: SEM analysis. Compacted particles from the surface Table 4: EDS analysis (weight \%) of areas shown in the Fig. 21. crust $-170 \mathrm{X}$.

\section{DISCUSSION AND CONCLUSIONS}

he high corrosion resistance of Fe-Cr-Mo alloys has been ascribed to the rapid formation of a uniform, highly protective passive film [11]. The pipe's hardness and resistance to various forms of corrosion are determined by the composition of the passive film (oxide layer) and play an important role in determining the lifetime of these 
pipes. The thermal stability of the oxide layer is influenced by the composition and thickness of the oxide layer as well as the bond to the underlying metal [6].

Determining factors for the high temperature corrosion are generally: metallurgy, TAN (chloridric and naphthenic acid), local flow conditions, sulphur compounds [12]. Sulphur compounds, originated from crude oils, include poly-sulphides, mercaptans, aliphatic sulphides, disulphides and thiophenes. The interaction of $\mathrm{S}$ with metal and protective passive film are of significance to the corrosion process since the presence of impurity elements, especially $\mathrm{S}$, at the metal-oxide interface is associated with the instability of oxide over layers and the spallation of the oxide at high temperatures [6].

Moreover, naphthenic acid corrosion (NAC) and sulphidic corrosion (SC) usually occur in some similar environments and the interaction between them is an important topic for refineries [13].

The composition of protective passive film (scale), for an oxidation temperature below $400^{\circ} \mathrm{C}$, consists mainly of $\mathrm{Fe}_{2} \mathrm{O}_{3}$, possibly $\mathrm{Fe}_{3} \mathrm{O}_{4}$ and small amount of $\mathrm{Cr}_{2} \mathrm{O}_{3}$.

Due to the penetration and the following protective scale's fracture, the underlying metal layer is attacked [14]. In fact, the scale becomes extremely porous and no more protective.

The environment's acidity, due to the presence of chloridric [15-16] and naphthenic acids, is one of the most important causes of this penetration through the scale. The aforementioned corrosion is pitting like, localized between scale and base material, typically close to the grain boundaries or inclusions. A considerable dissolution of metal compounds takes place in such areas: this dissolution provokes the solution acidity to increase inside the pit. Moreover, the concentration of aggressive anions increases, due to migration from the bulk, hence solution becomes more corrosive and the pit moves ahead quickly. High temperature promotes this mechanism.

According to the technical literature, the condition of pipes, when examined, after a long period in high temperatures and with the aggressive charge in the last two operating years, shows a clear pitting corrosion (see Fig. 4, 5, 6) with a strongly discontinuous and porous scale. Due to conspicuous infiltrations, this scale involves the formation of a pit under the deposit itself and even attacks grain boundaries (Fig. 8).

The Scanning Electron Microscope (SEM) and Energy Dispersive Spectrometer (EDS) analysis, executed on the craters of pits (see Fig. 10-11), clearly highlight the oxidized layer characterized by a porous and sponge-like structure. Moreover, the presence of chromium, oxygen and sulphur, shown by data, confirms oxides of iron and chromium as corrosion products.

On the other hand, the Scanning Electron Microscope (SEM) analysis performed on the section of the pit (see Fig. 13-14) highlights the corrosion products present in the inner part of the cavity.

The EDS analysis executed on areas where the scale is still compact (Fig. 15, Tab. 2 - Pt 1) highlights greater chromium's concentration (maybe $\mathrm{Cr}_{2} \mathrm{O}_{3}$ ) than that on areas less compact that is to say where the scale is strongly attacked and penetrated where oxidation is generated by $\mathrm{Fe}_{2} \mathrm{O}_{3}$ and $\mathrm{Fe}_{3} \mathrm{O}_{4}$ (Fig. 15, Tab. 2 - Pt 3-4).

Mapping of a section of the crust has been performed (Fig. 18) in order to perform a more accurate investigation of the crust itself.

It shows sulphur presence (sulphur compounds) in all non homogeneous scale, and a build-up immediately beyond the compacted one.

The examination of the materials shows an ongoing highly developed corrosive process.

In fact, looking at the first two operating years, Arabian Light crude and Arabian Medium crude constituted the only feed charges. A very low crude acidity level and a low Sulphur level (TAN $=0.1 ; \mathrm{S} \%=2.12$ ) feature both the abovementioned crudes.

Feed charges made up of much more aggressive crudes were adopted in the last two operating years $(\mathrm{TAN}=0.39 ; \mathrm{S} \%=$ $3.3 \%$ ).

These new environmental conditions provoked a heightened corrosive process, as shown by the analysis results. The severe fragmentation of the protective scale features the abovementioned heightened corrosive process, leaving behind sulphur compounds and severe pitting effects.

\section{REFERENCES}

[1] J. Hilkes, V. Gross, In: IIW Conference, Singapore, (2009).

[2] Metals Handbook, Properties and Selection: Irons, Steels, and High-Performance Alloys, 10th ed., ASM International, Materials Park OH, 1 (1990) 140.

[3] A.P. Greeff, C.W. Louw, J.J. Terblans, H.C. Swart, Corrosion Science, 42 (2000) 991. 
[4] N. Birks, G.H. Meier, Introduction to High Temperature Oxidation of Metals, $1^{\text {st }}$ ed, Edward Arnold, London, (1983) 110.

[5] J.C. Scully, The Fundamentals of Corrosion, $3^{\text {rd }}$ ed, Peragon Press, Oxford, (1975) 32.

[6] H. Cabibil, J.A. Kelber, Surf. Sci, 329 (1995) 101.

[7] B.P. Somerday, "Technical Reference on Hydrogen Compatibility of Materials; Low-Alloy Ferritic Steels:Tempered Fe-Cr-Mo Alloys", Sandia National Laboratories.

[8] A. Momber, Materials and Corrosion, 61 (2010) 9999.

[9] J. Torrent, V. Barrón, In: Encyclopedia of Surface and Colloid Science, Copyright D by Marcel Dekker, Inc. (2002).

[10] A. C. Scheinost, D. G. Shulze, U. Schwertmann, Clays and Clay Minerals, 47 (2) (1999) 156.

[11] A.P. Greeff, C.W. Louw, H.C. Swart, Corrosion Science, 42 (2000) 1725.

[12] D.R. Qu, Y.G. Zheng, H.M. Jing, Z.M. Yao, W. Ke, Corrosion Science, 48 (2006) 1960.

[13] J. Gutzeit, Mater. Perform., 16 (10) (1977) 24-35.

[14] Y. Kawahara, Corrosion Science, 44 (2002) 223.

[15] M.A. Uusitalo, P.M.J. Vuoristo, T.A. Mäntylä, Corrosion Science, 46 (2004) 1311.

[16] H.J. Grabke, E. Reese, M. Spiegel, Corrosion Science, 37 (1995) 1023. 